for poor patients where "all cases would, of course, be notified by the officials." But why "of course"? Would not some of the above objections hold just the same? Under what Act would they be notified? 2. Advanced cases to be compulsorlly removed to an institution. 3 Consump. tive persons to be prevented from working at a dairy farm or having anything whatever to do with the handling of meat, milk, or other food. 4. Disinfection of houses after death. 5 . Compulsory inspection of hotels and boarding houses. 6. Separation of children from consumptive adults. How all these good works are to be accomplished without compulsory notification and its consequent powers is not quite clear. How are health authorities to hear, otherwise, of all the cases and houses for which such measures are desirable? But, indeed, Dr. Raw appears in the end to favour a modified form of compulsory notification, and two of the chief reasons for such notification were embodied in the resolution of the Congress.

Greatly interested in the discussion of this vital subject, I am, Sirs, yours faithfully, EDMUND M. SMITH, Medical Officer of Health of the City of York. Health Office, Guildhall, York, Nov, 18th, 1907.

\section{THE ARMY AND NAVY MALE NURSES' COÖPERATION.}

To the Editors of THE LANCET.

SIRs,-May we beg the indulgence of your columns to appeal for funds for the Army and Navy Male Nurses' Coöperation? This society, which is honoured by the patronage of Her Majesty the Queen, is founded with the object of supplying to the public thorougbly well-trained male nurses and sick attendants of assured good character.

The personnel of the society is comp ssed solely of men who have been trained in the great military and naval hospitalsviz., of men of the nursing section of the army who have obtained their certificates of three years' training and, in the case of the navy, of members of the sick-berth staff who have completed their first term of service. The nurses on the register receive the full fees they earn, less a small reduction for working expenses. The Coöperation would appeal for help to those who feel that efficient male nurses should be more extensively employed in civil life, and that certain cases should not be nursed by women at all. It should appeal also to the many who wish to see employment found for men of exceptional character after they leave the two great services.

When the society is once started it will be self-supporting. Funds are needed to defray the initial cost of providing and equipping a suitable office to be available day and night, of advertisements, and of obtaining a small house where the men can lodge when waiting to be despatched to their cases. This latter requirement is essential in the interests of the patients served and for the securing of prompt response to all applications. It is estimated that the sum of $£ 2000$ will put the society upon a sound basis and enable it to commence its work at once.

Donations may be sent to the honorary treasurer at the office of the society, 47B, Welbeck street, Cavendish-square, London, W., where fuller information may be obtained. We beg to remain, Sirs, yours faithfully, Frederick Treves. HOWARD H. TOOTH.

\section{ON MOBILITY OF THE KIDNEYS.}

\section{To the Editors of THE LANCET.}

SIRs, - The communication on Mobility of the Kidneys by Dr. Hector Mackenzie, which appeared in THE LANCET of Oct. 26ch, $p$ 1140, afforded me great interest, more espe. cially as the conclusions at which he arrives and which are based on the examination of a large number of patients are at variance with my own in almost every particular with the exception that we concur in regarding the condition as one of frequent occurrence.

The history of my personal study of the subject of moveable kidneys is divided into three epochs: the first, during which $I$ regarded the condition as an anatomical curiosity; the second, when I had noted the frequency of its occurience; and the third, or present epoch, in which I recognise the clinical importance of its prestnce. Indeed, I believe that a considerable proportion of the chronic invalids who, classed indiscriminately as neurasthenics, wander from pillar to post in search of health are sufferers from symptoms of which moveable kidney is the cause.

The neurasthenic I regard as a sufferer from auto-intoxication, the toxins being excretory products which, instead of being normally excreted, are reabsorbed into the blood stream. Assuming that a healthy kidney is performing its excretory function in a normal manner but that owing to partial obstruction of the nreter by pressure on it of the inferior pole of a dropped kidney the free outflow of urine is impeded and a condition arises in which there must be reabsorption of excretory products. In this case the symptoms of auto infection are due to the dropped kidney impeding the outflow of urine. Again, the perinephritic fibrosis which frequently involves a slightly moveable kidney and is prob. ably the result of chronic intermittent friction may, and probably does, interfere with the normal excretory processes. So far the argument is based on a prinri evidence but the following case serves to show that a slightly moveable kidney may give rise to a train of marked symptoms from which relief may be obtained by fixation of that organ, even when the second kidney is highly moveable.

The case was that of a married woman, aged 37 years, The patient suffered with periodic headaches of such intensity that I feared she might be driven to do something desperate in order to terminate her sufferings. The abdomen was distended with gas, a condition which added greatly to her discomfort and suffering. As the case is reported in THE LANCET of April 9th, 1904, I will confine this account to its broad bearings on the present argument. I took the case to Professor Roux at Lausanne. In his clinique he made an examination of the urine escaping from each ureter separately by means of Luys's bi-ureteral collector, a pill of aniline blue having been administered 20 minutes earlier. The result of this examination was that about equal amounts escaped from each ureter but the secretion from the left one was the paler, a fact readily discerned by the unaided eye. To quote from the original report: "With these facts before us the question was whether the headaches depended on the condition of the kidneys, if on one more than the other, on which, and whether operative treatment was likely to afford relief." I decided that the left slightly moveable kidney was the one to select for operation and was relieved to find that Professor Roux had arrived at the same decision. The kidney was exposed, explored for calculus, freed from fibrous adhesions, and fixed in position. The result is that the patient has not had a bad headache from that day to this, four and a half years after the operation, her abdomen has returned to its normal girth, which affords her great satisfaction and she is able to fulfil her duties and enjoy life to the utmost; in fact, after leading a life of suffering for years, she is now a healthy and happy woman.

This case affords material for criticising many of the points touched on by Dr. Mackenzie. In the first place he would not have classified the left kidney in my case as a moveable kidney but as a "palpable kidney." Now the term palpable kidney, as used by Dr. Mackenzie, seems to me to be unsatisfactory, for it includes two conditions, viz, a slightly dropped kidney and a kidney which is not moveable, but which may nevertheless be felt on account of an abnormally low position or of slight enlargement. Clir ically the difference can be readily appreciated, for while the dropped kidney can be made to glide from between the two hands by exerting pressure with the finger-tips the fixed kidney will only recede with the movement of expiration to return with the succeeding inspiration. It does not move independently of the diaphragm. The term "palpable kidney" might be applied with equal force to the highly moveable kidney as to that which is but slightly moveable, but it is not a convenient term, for it neither necessarily includes all the degrees of moveable kidney nor does it exclude all the kidneys that are not moveable.

To pass on to another point. Dr. Hector Mackenzie seems to regard the degree of mobility of the kidney as the index of the gravity of the symptoms to which it may give rise. My observation has led me to take a view which is entirely opposed to this. The hivhly moveable or floating kidney seems to move about freely behind the coils of intestine without giving rise to the train of nervous symptoms which frequently coexist with the slightly moveable kidney. The former, indeed, may give rise to local signs and symptoms, such as thickening of the peritoneum, irritation of the bowels, occasional attacks of pain resembling renal colic and 